\title{
CAMOENS Y EL ESPÍRITU ÉPICO
}

Discutir el más antiguo problema de la ciencia literaria en torno al poema nacional de los portugueses es ya levantar la obra de Camoens al plano universal que le corresponde, como expresión fiel del espíritu del Renacimiento. En ottos lugares me he explicado mejor en cuanto a las razones críticas de este esfuerzo de universalización de los Lusiadas ${ }^{1}$. Universalización que no quiere decir difusión o propaganda para que el mundo conozca mejor el poema, sino simple reconocimiento del carácter supranacional o humano de su contenido emotivo.

\section{Platón contra Homero}

En nuestro linaje heleno-romano, el pensamiento maduró bajo la égida de la poesía homérica. Los griegos demostraron brillantemente que en una gran obra literaria se totaliza y juzga la existencia humana, y que de ese conjunto de síntesis valorativa en símbolos y ficciones se extrae una ética y una política o una norma y un plan de vida y su gobierno. No significa otra cosa el miedo de Platón a los poetas y la flagrante contradicción en que incurrió: rendir culto al mayor de los poetas y querer expulsarlos a todos de su ciudad ideal. Su miedo era un reconocimiento implícito de la fuerza y de la influencia de la poesía. Espíritu eminentemente poético, Platón sentía la seducción del genio de Homero y se defendía de él con energía:

Así, pues, Glauco, cuando encontrares panegiristas de Homero que digan que este poeta llevó a cabo la educación de Grecia, y que para administrar los negocios humanos o enseñar su manejo es justo, tomarlo en la mano, estudiarlo y vivir normando por él toda la existencia, debes por cierto saludarlos y acogerlos amistosamente, como a hombres que son tan virtuosos

- Véase $A$ épica portuguesa no século xvi, varias veces impresa desde 1930, y én edición definitiva por la Faculdade de Filosofia da Universidade do Estado de São Paulo, 1950. El subtítulo, Subsidios documentares para uma teoria geral da epopeia, muestra claramente el carácter del objetivo de mis estudios, más general que local. En $195^{1}$ publiqué un addendum, "Ainda a épica portuguesa (Nótulas de auto-crítica)", en el Homenaje a A. M. Huntington, en la Revista de História de São Paulo y en mis Estudos de literatura, 5a Série. 
como es posible, y concederles que Homero es el príncipe de la poesía y el primero de los poetas trágicos, pero también saber que en materia de poesía es preciso no admitir en la ciudad sino los himnos en honor de los dioses y los elogios de los buenos. $\mathrm{Si}$, por el contrario, admites la Musa voluptuosa, el placer y el dolor serán los reyes de la ciudad en vez de la ley y de ese principio que, de común acuerdo, hemos mirado siempre como el mejor: la razón ${ }^{2}$.

Esta resistencia es, en Platón, una idea fija. El proceso contra Homero y los poetas es regular y prolijo, pero la sentencia se pronuncia inmediatamente después de la enumeración de los males de la poesía y mucho antes de la declaración de las razones doctrinarias de tal severidad. Los poetas son mentirosos. El acusador se limita al examen de las fábulas grandes, las de Homero y Hesíodo entre otros: representan mal a los dioses y a los héroes, atribuyéndoles pasiones indignas de ellos; a los poetas debe obligárseles a componer fábulas de fines educativos; es preciso fiscalizar las pinturas del Hades, para que el pavor de la muerte no lleve a los futuros guerreros a preferir la derrota y la servidumbre a la muerte. No menos peligrosa es la forma, porque de las tres especies de poesía -imitativa por el diálogo, como la tragedia y la comedia, expositiva o narrativa, como los ditirambos, y mixta, como la epopeya-, adolecen del vicio de la imitación precisamente las dos más peligrosas, el drama y la epopeya. Ahora bien, los guardianes de su ciudad ideal no pueden imitar nada ni a nadie. Por eso al poeta se le debe saludar en voz baja como a un ser sagrado, y deportarlo a otra ciudad, después de coronarlo con guirnaldas y de derramar mirra sobre su cabeza.

En el libro X, volviendo a la cuestión, el filósofo advierte que la perfecta corrección de su ciudad exige que se excluya la poesía imitativa de su seno. Hay tres grados de creación: el prímero es de carácter divino, porque es la fijación primera de las ideas o de los arquetipos eternos y únicos de las cosas; el segundo es la realización aproximativa e ilimitada de esos modelos ideales, y de cuantos hacen cosas sobre la tierra partiendo de singulares y absolutos conceptos; y el tercero y más bajo es el que parte de la imitación de esa realización humana del pensamiento divino. Homero, y con él todos los poetas y los demás artistas, no pasan de ser simples obreros de imágenes o artífices de imitaciones de imperfectas realizaciones imitativas de las ideas divinas. Si sabía tanto del gobierno de las ciudades, del mando de los ejércitos, de administración y legislación, ¿por qué prefirió vagar de ciudad. en ciudad, ciego recitador de sus fábulas, en

${ }^{2}$ Libro III, pág. 95 de la nueva y preciosa traducción, con introducción crítica y notas de Robert Baccou, Paris, 1950. 
vez de dedicarse al noble arte de dirigir a los hombres y de serles útil? Los poetas son imitadores de segunda mano e imitadores de los sentimientos inferiores, los más fáciles de imitar y los más accesibles o inteligibles para la multitud. El poeta imitador no tiene cabida en un Estado regido por leyes sabidas, pues introduce un mal gobierno en el alma de cada uno, lisonjea la parte irracional del hombre $y$, lejos de distinguir lo mayor de lo menor, vive en un mundo de fantasmas, a infinita distancia de la verdad; agrandando o empequeñeciendo la realidad.

EPOPEYA Y JUVENTUD

Lo que someramente hemos descrito arriba fué un choque entre la realidad de una ficción y la ficción de una realidad. No hago juegos de palabras. Realidad de una ficción es la existencia real de los poemas homéricos, invadiendo y dominando el espíritu de los viejos helenos; ficción de una realidad es la fantasía platónica de la realidad de un Estado, la ciudad justa que nos construye en la República.

Pero debemos subrayar la exacta noción de poesía épica que demuestra Platón. La epopeya, celebración poética de hechos prodigiosos en que intervienen los dioses, transcurre en dos planos: el plano lógico o realista y el plano alógico, divino o sobrenatural. La evidencia elocuente de los valores poéticos del primer plano hace que la epopeya sea un cuadro de realidad viva, y al mismo tiempo, bajo el impulso de la expresión imperativa del arte, un código moral de honra y de modos de convivencia y de gobierno. Este contenido explica la fuerza y la influencia de la epopeya y provoca la condena de Platón. En su argumentación está implícita una rendida alabanza al genio de Homero: el poeta conocía muy bien a los hombres del plano lógico y sus ideales de vida, y conocía igualmente bien a los dioses del Olimpo, los caracteres y las proezas que los hombres les atribuían. Los dos planos se interpenetran y se perturban mutuamente: de ahí las inverosimilitudes y los golpes mágicos y traicioneros de los dioses, que tanto impresionan al filósofo. $Y$ en cuanto al plano estrictamente lógico, la zona en que los héroes hijos de dioses se conducen como hombres, el poeta llevaba a las últimas consecuencias sus conceptos de la vida, haciéndolos violentos, crueles, interesados e injustos. $\mathrm{Y}$ todo ello ganaba un esplendor nuevo por la expresión formal: cuando Platón escribe estas líneas: “ . . despojadas de su colorido artístico y citadas por el sentido que encierran, tú sabes ... qué figura hacen las obras de los poetas", está reconociendo la unión indisoluble de la forma y del fondo de la obra de arte.

En medio de las nieblas ilusorias de su utopía, mucho más ilusorias que las ficciones homéricas, Platón metía una cuña entre el 
plano de la acción y el plano de la composición o estructura de lás epopeyas; pero no conseguía apartarlos, porque son inseparables. Platón no podía saber lo que hoy sabe cualquiera: que la poesía épica es una fiebre de la juventud de los pueblos, un delirio de creación alógica de los tiempos primitivos o heroicos de los pueblos cuando la guerra es el factor principal de su formación moral y de su progreso; que en todas las civilizaciones más o menos autónomas hay un foco épico, y que esas fermentaciones del espíritu heroico, en Occidente como en el viejo Oriente, dentro o fuera de la tradición clásica, tienen caracteres comunes: apología de la violencia, realismo fiel al lado de lo maravilloso, intrusión del mundo sobrenatural de los dioses creados por instintos primitivos de miedo ante la naturaleza, agüeros, profecías, énfasis oratorio, formalismos y simbolismos. Si hubiera germinado el esfuerzo de análisis crítico de la República, la epopeya estaría muerta. Pero el espíritu épico y el espíritu crítico son adversarios. Y la experiencia de los pueblos no se transmite en línea recta: hay desperdicios, olvidos, colapsos en el fluir de la historia. Cada pueblo tiene su juventud propia y debe aprender por su esfuerzo, como los individuos. La larga Edad Media fué un ejemplo magnífico de esta verdad.

En la Edad Media - tomo esta designación en su sentido restringido o tradicional y no en el sentido amplio de juventus mundi que le atribuye Waldemar Vedel ${ }^{3}-$, en la Edad Media, época discontinua o desarticulada de la experiencia de los antiguos, se encendieron nuevos focos de fermentación épica que repiten las características de los antiguos, esto es, que idealizan un mundo moralmente hermano del mundo homérico. El injerto nuevo del cristianismo, en vez de oponerse a ello, suministra un nuevo valor maravilloso que refuerza el plano alógico. Vedel ha descrito el contenido ideal del espíritu heroico poniendo la vista en todos los tiempos y en todos los lugares. Aquiles, Roldán, Sigfrido, Bernardo del Carpio y Rustem se emparientan por las afinidades de sus caracteres, por su psicología, aunque se distingan por su modo de hablar, por su indumentaria, por su religión. Y análoga es también la influencia formadora sobre la colectividad, influencia moral, social y política.

Cuando el Renacimiento restablece los valores poéticos de la

${ }^{3}$ La obra original de Vedel es Helteliv (Copenhague, 1903); pero lo que nos llegó, en los países ibéricos, fué la serie Ideales culturales de la Edad Media (4 vols., Barcelona, 1925-1931), que no creo que correspondan a aquélla: el primer volumen traducido, La vida de los héroes, es resumen de la obra publicada en 1903; el segundo, Romántica caballeresca, se presenta como traducción, sin declaración de la lengua de proveniencia; el tercero y el cuarto, La vida en las ciudades y La vida monástica, se presentan como "adaptados del danés". Todos carecen de aparato crítico, deficiencia lamentable en una obra de tal importancia. 
Antigüedad y Petrarca revela los poemas homéricos, y cuando las grandes empresas geográficas dan un sentido nuevo al espíritu guerrero y de aventura, se enciende un nuevo foco. Esta fermentación épica se encuentra con dos planos alógicos, sobrenaturales o maravillosos: el pagano ejemplificado de manera tan brillante en Homero y el cristiano heredado de la Edad Media y ya probado en las canciones de gesta y en las vidas de santos. Y los poetas épicos elaboran los dos planos maravillosos, porque esa dualidad existía en el propio espíritu de la cultura del Renacimiento; además, los dos planos habían coexistido pacíficamente en la precursora cultura de la Provenza de los siglos XI y xir. Ahora intervenían, ayudaban y combatían entre los héroes, no sólo los dioses del Olimpo, sino también los apóstoles y los santos, la Virgen, el propio Jesús.

Esto nos llevaría otra vez a la coexistencia de los dos planos maravillosos en los Lusiadas, trillado problema estético que sólo subsiste para quien lee una vieja epopeya con el criterio del lector de la novela burguesa del siglo xIx, del lector educado por las novelas del realismo francés. El poema nacional de los portugueses tiene que venir a colación, pero por otros motivos.

\section{ESPÍRITU ÉPICO Y ESPÍRITU CRÍTICO}

A fines de la Edad Media el ideal heroico estaba desacreditado, y agotadas las fuerzas creadoras de la poesía épica. Al ideal heroico ya había sucedido el ideal caballeresco, y éste, a su vez, había degenerado. Cervantes esgrimía contra un difunto. Triunfaba el espíritu burgués, nada heroico, con sus ideales de paz y trabajo. La efervescencia épica del Renacimiento es completamente artificial: proviene de importación erudita y data del Africa de Petrarca, y principalmente del deslumbramiento producido por los poemas homéricos. Poco a poco fué surgiendo un largo venero de poesía épica, apoyada en el patrimonio de la cultura antigua: los poetas cíclicos posthoméricos, Hesíodo, Livio Andrónico, Varrón de Atax, Virgilio, Lucano, Valerio Flacco, Silio Itálico, Estacio, Claudiano.

Pero la civilización europea había salido de su juventud, esto es, había sobrepasado aquella fase de forja creadora de los espíritus nacionales, con sus luchas y sus odios, sus traiciones y sus heroísmos. La poesía, como sueño lírico y como fantasía épica, había perdido crédito ante el espíritu monástico y ante el espíritu burgués. El foco poético de Provenza había sido extinguido por la intolerancia. Las autoridades religiosas se conjuraban contra la mentira y la inmoralidad de la poesía. Fué necesario descubrir sentidos alegóricos o forzar la interpretación de los poemas para darles alguna posibilidad de defensa contra la general condena. El comienzo de esta larga defensa de la poesía fué la Genealogia deorum gentilicorum de Boc- 
caccio, que Betussi tradujo y publicó en Venecia en 1574; y le siguieron otras, verdaderos tratados de estética de la poesía, como los de Eneas Silvio, de Sidney, de Harington ... Sin embargo, quienes lograron el restablecimiento de sus créditos fueron, más que los autores de defensas eruditas de la poesía, los poetas italianizantes y platónicos, los que se inspiraron en Dante, en Petrarca y en el viejo Platón. Es ésta una de las grandes paradojas de la historia de las ideas: que el gran adversario de la poesía fuese su gran animador en el distante siglo XvI, cuando sobre la negación de la República prevaleció la apología del amor del Banquete, que determinó una corriente estética amplísima en las literaturas neolatinas. Interpretación teórica de esta corriente son los Diálogos de amor de León Hebreo. Y otra paradoja, casi tan grande, es la de la situación de la poesía épica en esta edad áurea de la inteligencia creadora y del espíritu crítico. Jamás ostentará la historia humana una sucesión inmediata de cuadros tan contrarios como el del espíritu medieval y el del espíritu renacentista. Moría o se desacreditaba casi todo lo que había constituído el ambiente formador de la poesía épica.

Pero ésta, aliada natural de todo ese primitivismo acrítico, ocupaba un noble lugar en el patrimonio de los antiguos. A los modernos imitadores de ese patrimonio tocaba restablecer el gusto épico. $\mathrm{Y}$ entonces la poesía épica, que para los antiguos había sido un género vivo, nacido de una realidad social, cayó en una imitación fría, puramente estética, a la manera de la tragedia y de la comedia concebidas con los ojos puestos en un mundo mitológico en que nadie creía y en un mundo social absolutamente extinguido. Petrarca componía su Africa en este total enajenamiento de su medio, pero demostraba la nobleza del género, con una riqueza expresiva que descubría un mundo literario nuevo. Los poetas italianos del siglo $\mathrm{xv}$ intentan una nacionalización de la epopeya por medio de la adopción de temas peninsulares, pero perfilando los recursos expresivos de Petrarca, por ejemplo el del sueño. Vemos, pues, la amplia utilización poéticà del sueño y también de la isla afortunada o de los amores en poemas de materia histórica moderna y hasta contemporánea, para adulación de los mecenas, en Maffeo Vegio, en Basinio Basini, en Filelfo, en Porcellio, en Cornazzano ... ${ }^{4}$ Pero estos poemas no eran epopeyas, sino poemas históricos o crónicas rimadas, con ciertos artificios de composición tomados de la epopeya clásica y empleados de manera arbitraria, porque aún no los había fijado una estética o arte poética. La directa y devota imitación suscitaba una serie de problemas estéticos, y éstos exigían un profundo discernimiento crítico para llegar a la esencia del arte de los antiguos y salvaguardar la libertad en la imitación. Tal fué la gran cualidad

\footnotetext{
+ Véase Antonro Brlloni, Il poema epico e mitologico, Milano, s. f.
} 
de los italianos. Tasso es una cumbre de interpretación crítica y de realización poética. En su tiempo hay ideas muy claras sobre la estructura y la esencia del poema épico, sobre sus relaciones con la historia y sobre las reglas de su composición ${ }^{5}$. Sólo que la epopeya del Renacimiento, la verdadera epopeya de comunión cívica, enraizada en un suelo y extendiendo sus ramas en el cielo de todos, no había sido creada todavía.

Y no lo había sido porque ni siquiera existía el suelo en que pudiera enraizar. Los grandes poemas de Pulci, Boiardo y Ariosto, al idealizar la figura de Roldán, plagiaban, por decirlo así, la épica medieval: expresaban el viejo concepto caballeresco con toda la opulencia del estilo poético nuevo, pero sin poder atribuirle el significado humano que había tenido para los hombres de la Edad Media; eran superiores y aun geniales ejercicios de estilo; eran hipertrofias de los temas legendarios, caballerescos y religiosos de la épica y de la novelística medievales, pero no reflejaban fielmente las inquietudes del hombre renacentista, que no creía ya en Carlomagno, ni en Roldán, ni en la caballería, ni en las cruzadas; iban al contenido artístico de los temas, con una libertad y una destreza que los poetas medievales habían desconocido. Éstos habían dejado morir su género de agotamiento, cuando todavía tenía tanto que dar, en glosas formales. Vedel ha esbozado el cuadro moral y social fundado sobre los ideales implícitos en esta poesía. Podría habernos dado un índice de temas de la poesía y de la hagiografía medievales, o, mejor, de las situaciones obligadas o toleradas por el gusto público, algo parecido al inventario de Polti sobre el teatro y al índice de Thompson sobre el folklore universal ${ }^{6}$. El lugar del poeta épico del Renacimiento seguiría siendo vago si en un rincón de Europa no se hubieran verificado las condiciones necesarias para el surgimiento de una verdadera epopeya, viva por tener sus raíces en un suelo y sus ramas ondeantes en el cielo de todos, agitado por una gran emoción humana.

\section{La paradoja portuguesa}

Una nueva paradoja nos sale al paso: un pueblo que en pleno Renacimiento vive arcaica o anacrónicamente sus tiempos heroicos. En el extremo occidental de la Península ibérica, en su faja atlán-

5 Belloni, op. cit., págs. $118-141$.

${ }^{6}$ Georges Polti, Les trente-six situations dramatiques, nouv. éd., Paris, 1924; STrтн Thompson, Motif-index of folk-literature, Bloomington, Indiana, 6 vols., 1932-1936. La obra de Thompson es un verdadero ejemplo de organización metódica, basada sobre amplísima información; sólo es de lamentar que sea tan pequeño el espacio concedido al folklore portugués, representado simplemente por una recopilación de Z. Consiglieri Pedroso. 
tica, había surgido a principios del siglo XII una nueva nacionalidad, por un proceso análogo al de la separación de Castilla del reino leonés. Pero las luchas entre Castilla y León, y entre moros y cristianos, desde tiempos del rey Rodrigo, habían creado todo un ciclo épico, del cual quedan cinco grandes gestas y la pulverización de otras en los llamados "romances viejos"; y las luchas entre portugueses y leoneses (y luego castellanos) y entre los mismos portugueses y los sarracenos no sólo no despertaron el entusiasmo épico, sino que tampoco impidieron la floración de un exuberante lirismo que usurpa su lugar. $\mathrm{Y}$, al contrario de lo que generalmente se observa en la historia literaria de los pueblos, la expresión poética de los portugueses nace bajo forma lírica extranjera o de importación. Como la floración épica es consecuencia de un estado social y espiritual de exaltación bélica y heroica, fué preciso esperar a que esta exaltación viniera. Y vino más tarde, entre 1480 y $155^{\circ}$, desde la oficialización de las empresas ultramarinas y la evidencia de sus lucros y novedades deslumbradoras, a través de la embriaguez de los triunfos del apogeo, hasta el caer de las sombras de la Contrarreforma. En esos decenios el pequeño pueblo sale de su anonimato peninsular y de su lucha fronteriza, de su pobreza de agricultor rutinario, y se lanza a la vida de aventura cosmopolita, de conquista y de riqueza, todo a costa de esfuerzos sobrehumanos de energía, verdaderamente desproporcionados con la escasez de gente y de dinero. Todas las fuerzas de Portugal se polarizan en este sentido, el viaje marítimo y la guerra ultramarina. Y este grupito humano, desterrado en el extremo occidental de Europa, adonde llegaban amortiguados los reflujos del movimiento de la historia general, adolece de una psicosis heroica: convicción de superioridad y hasta de predilección en la corte del cielo, de donde le venía frecuente auxilio; opción por la vida incierta de los combates con los hombres y las fuerzas de la naturaleza; desfiguración de los sucesos y de las figuras históricas, convertidas de grandes en gigantescas; y, por último, la presunción de haber sobrepujado los valores heroicos de la Antigüedad, expuestos en los poemas de Homero y Virgilio y en la historiografía griega y romana ${ }^{\top}$. Los portugueses de entonces, grandes realizadores, vivían fuera de la realidad. Y una de las mejores pruebas de ello es su desconocimiento de la importancia del Brasil, descubrimiento ofuscado durante mucho tiempo por el espejismo de la India. Fidelidad a la época y anacronismo, hasta llegar a la locura heroica del rey don Sebastián, que era un espíritu medieval. Esta psicosis produjo un conjunto de ideas e interpretaciones estéticas o de mitos,

` Este ambiente de febril heroísmo se rastrea literalmente por los índices o síntomas que enumeré en mi Épica, ed. de 1950, págs. 63-343. 
falsificaciones históricas, oficiales y colectivas, que mueven a Camoens; y produjo también una red de prejuicios y de ideas falsas sobre la vida y la función de los pueblos y de los príncipes, que llevó a la locura de don Sebastián. Así nació el poema nacional: nacional por su procedencia legítima del ambiente legendario del pueblo portugués, renacentista por su fidelidad al espíritu del Renacimiento. Ni la supervivencia de los temas carolingios, ni el descubrimiento de América, ni la victoria de Lepanto produjeron esa necesaria efervescencia legendaria; sólo el espejismo de la India.

Para comprender bien esta paradoja de la presencia de un pueblo atacado de fiebre heroica en pleno Renacimiento, es necesario atender a lo que había de nuevo, adherido a ese arcaico heroísmo. Los portugueses restablecían, hasta cierto punto, el concepto guerrero de la existencia, según la alta Edad Media, en que el asalto, la conquista y la depredación hacían ley; pero llevaban la guerra lejos del mundo europeo, a escenarios exóticos, y aliaban a la guerra dos instrumentos nuevos de civilización, que habían surgido después de los largos siglos heroicos: el comercio internacional y el capitalismo. Creyendo servir a su fe, servían a su pobreza y a esos nuevos aliados.

El poema de Camoens fué una reacción de salud o de genio en medio de la dolencia general. Y ese carácter de salud espiritual se manifiesta en la moderación del uso que el poeta hace del material épico. Desdeña las ordinarias adherencias del espíritu épico, los agüeros, los prodigios y hechicerías, la individualidad sobrenatural de los caballos y de las armas, las intervenciones divinas que en los combates ayudan y advierten a los héroes; fué infiel al conjunto ortodoxo de las fermentaciones épicas, pero fiel al espíritu nuevo del Renacimiento, que era eminentemente crítico. Y esa infidelidad estética es la que permitió la presencia de tan fuertes elementos líricos y autobiográficos en la epopeya. De la misma infidelidad a la riqueza heterogénea de las fermentaciones épicas nació su escrupulosa historicidad; dentro de los artificios clásicos y de los recursos de composición -sueño, consejos e intervención de los dioses, profecía, tempestad, mito de Adamastor, exposición de banderas pintadas-, el poema acata rigurosamente la verdad histórica. Y este historicismo es anti-épico, significa incluso la intrusión de un factor de descomposición del espíritu épico. Lo que hay de épico es el punto de vista desde el cual se presenta la materia histórica, es el entusiasmo engrandecedor, la elocuencia ufana de los héroes y la elocuencia panegírica del propio poeta, es la concepción heroica de la totalidad de la vida de un pueblo.

Renacimiento quiere decir nacimiento nuevo del hombre a una vida más grande. En Portugal se vivió una vida típicamente renacentista, vida gloriosamente nueva, y por eso la epopeya de Camoens 
es la epopeya auténtica del espíritu renacentista, a pesar de las sombras que ya caían sobre él. Después de los Lusiadas, se precipita sobre el género el viejo plano maravilloso de las extinguidas fermentaciones épicas, y engrosa la tendencia historicista. Las alegorías de los poemas posteriores, numerosos y soporíferos, a nadie emocionaban, y contradecían las luminosidades críticas del Renacimiento; y la creciente historicidad de los poemas, convertidos en crónicas metrificadas con algún artificio de composición, aprendido en los preceptistas, significaba un largo proceso de descomposición del espíritu épico. Algo parecido será el predominio del espíritu histórico $\mathrm{y}$ arqueológico en la novela histórica del siglo xx. Se pretendía enseñar historia y conferir una glorificación convencional a los héroes o a las grandes figuras, heroísmo y grandeza personalmente elegidos por el gusto del poeta-cronista, independientemente de toda sanción anterior o posterior de la opinión colectiva.

No tenemos una épica medieval y somos, por eso, extraños a la multiplicidad de sus problemas; pero tenemos un ciclo épico renacentista, contradictoriamente anacrónico y actual, fracasado y una vez triunfante por una obra de genio que nos articula con el gran resplandor del Renacimiento, en plena independencia de la épica de Castilla, de la vieja y de la nueva. La historicidad, que Menéndez Pidal insiste en considerar como manifestación de la constante austeridad estética y del verismo de la poesía ibérica, desde los prístinos tiempos de la literatura hispanolatina, se me figura más bien a mí, data venia, como la presencia obstinada de una fuerza anti-épica, en espera de su hora de desquite, y, después de la epopeya portuguesa, gozándose sobre el cadáver de su gran enemiga, la imaginación heroica. Algo que evoca la lucha entre los géneros literarios, idea de Brunetière que habría que restaurar con argumentos nuevos.

Por el contrario, el sistema de ideas del eminente maestro espanol, ampliado en su aplicación a un horizonte espacial y temporal mayor que Castilla, conduce a la rehabilitación de la epicidad de la Farsalia de Lucano y al establecimiento de un paralelo igualitario entre los Lusiadas y la Araucana, paralelo imposible fuera de esas ideas. El poema de Ercilla, tan fatigoso y desarticulado, ejemplificará más bien el proceso de disolución del espíritu épico de tono arcaico y la gran novedad de la entrada del exotismo americano en la poesía clásica.

La mente humana vive en incesante elaboración de mitos, bajo el estímulo del entusiasmo que dora los momentos mejores de la existencia. Parece como si la vida según la verdad desnuda y cruda fuera imposible. El espíritu crítico es vencido a cada hora, pero no muere. El Renacimiento fué una gran pugna entre el espíritu heroico y el espíritu crítico. El poema de Camoens refleja esa pugna: un puñado 
de verdades en una armazón de mentiras. Coexistencia libre de los dos planos. Noble tarea la de la crítica portuguesa, tarea más interpretativa que erudita: universalizar los Lusiadas por la humanidad de su contenidos.

Universidade de São Paulo.

Fidelino de Figueiredo

${ }^{3}$ El gigante Adamastor deberá mencionarse en obras del tipo de la de Herbert Spencer Robinson y Knox Wilson, Myths and legends of all nations, New York, $195^{\circ}$, sobre todo si los autores ensanchan un poco más el ámbito de su libro para considerar tambićn los mitos y leyendas de origen literario. 